\title{
Nucleobase-dependent Reactivity of a Quinone Metabolite of Pentachlorophenol
}

\author{
V. G. Vaidyanathan, ${ }^{\dagger}$ Peter W. Villalta ${ }^{\dagger}$ and Shana J. Sturla ${ }^{*}$, \\ Department of Medicinal Chemistry, College of Pharmacy, and The Cancer Center, \\ University of Minnesota, Minneapolis, Minnesota 55455
}




\section{Contents}

Figure S1. HPLC chromatogram of dCyd adducts. (A) Adduct 3 from the crude mixture

(B) After separation of adduct $\mathbf{3}$ from MPLC, adducts $\mathbf{1}$ and $\mathbf{2}$ were separated from the crude mixture and injected in HPLC column

Figure S2 Electronic absorption spectra of adduct $\mathbf{1}(29 \mathrm{~min}), \mathbf{2}(24 \mathrm{~min})$ and $\mathbf{3}(20 \mathrm{~min})$

Figure S3. ${ }^{13} \mathrm{C}$ NMR of adduct ${ }^{13} C_{6}-4$

Figure S4. Typical UV absorption spectra of (A) adduct 5 and (B) adduct 6 from the reaction of 2'-deoxyguanosine $3^{\prime}$-monophosphate with $\mathrm{Cl}_{4} \mathrm{BQ}$. Reaction was carried out in $10 \mathrm{mM}$ ammonium formate, $\mathrm{pH} 6.0$ at $37^{\circ} \mathrm{C}$,overnight.

Figure S5. Selected ion monitoring (SIM) of DNA adducts from the reaction of $\mathrm{PCP} / \mathrm{HRP} /$ peroxide with DNA or dG in $10 \mathrm{mM}$ phosphate buffer, $\mathrm{pH} 7.4$ at $37{ }^{\circ} \mathrm{C}$ for 1 week. (A) 5 in $\mathrm{dG}$, (B) in DNA. The $\mathrm{m} / \mathrm{z}$ values are labeled.

Figure S6 (A) Plot of time vs. relative level of $\left[\mathrm{Cl}_{4} \mathrm{BQ}\right] /[\mathrm{PCP}]$. (B) Plot of $[\mathrm{HRP}] v s$. relative level of $\left[\mathrm{Cl}_{4} \mathrm{BQ}\right] /[\mathrm{PCP}]$ formed 
Figure S1.

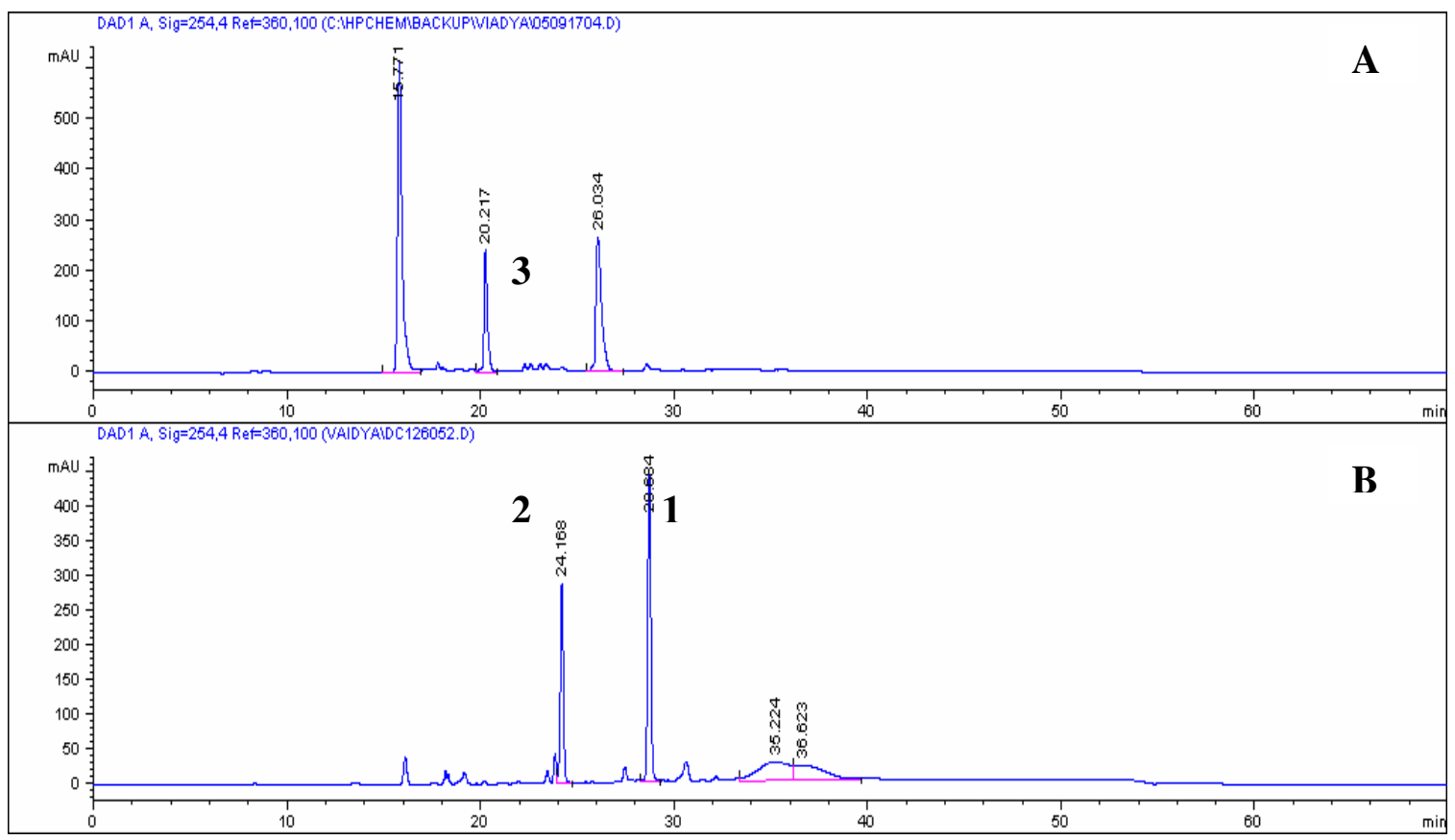


Figure S2

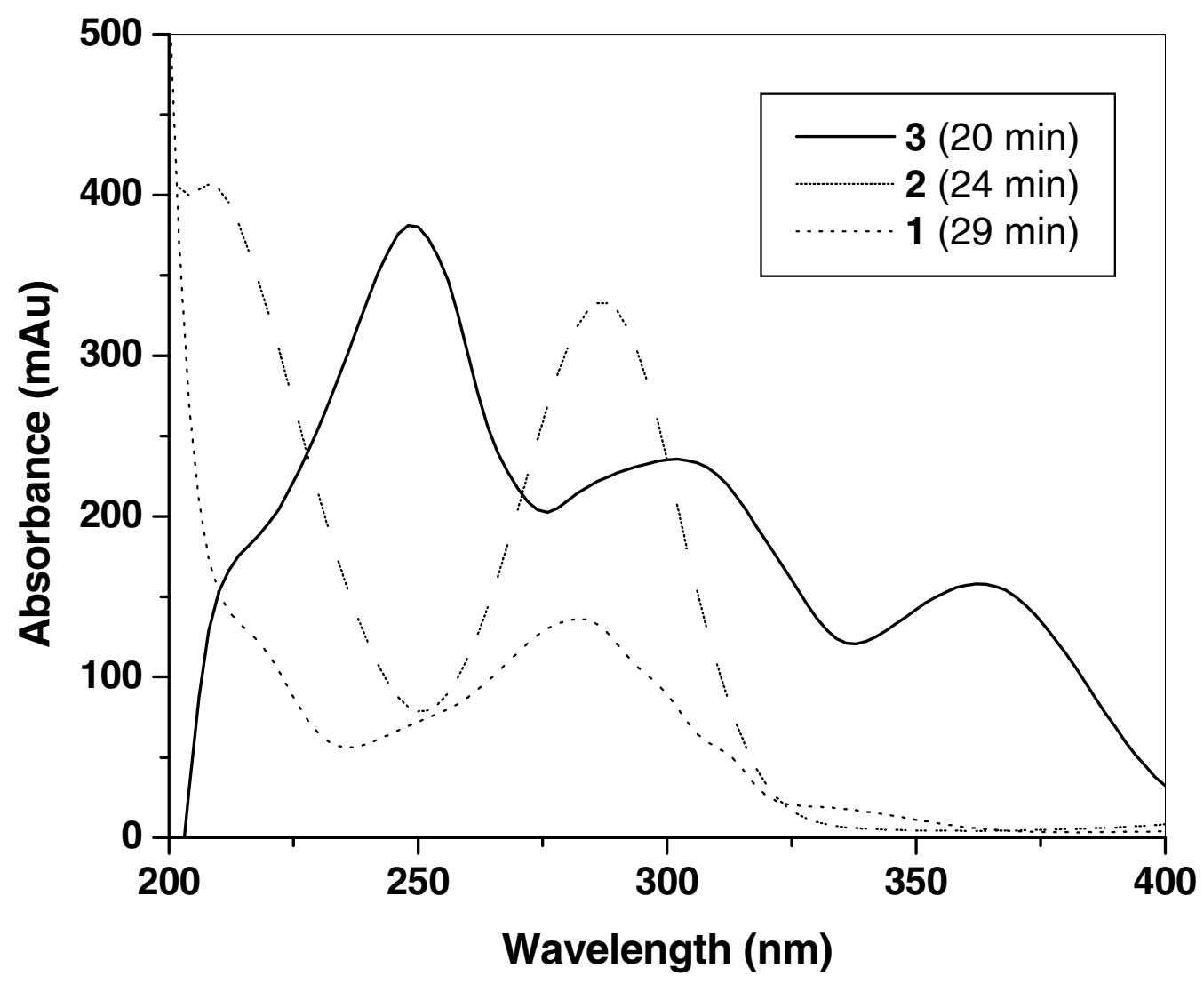




\section{Figure S3}
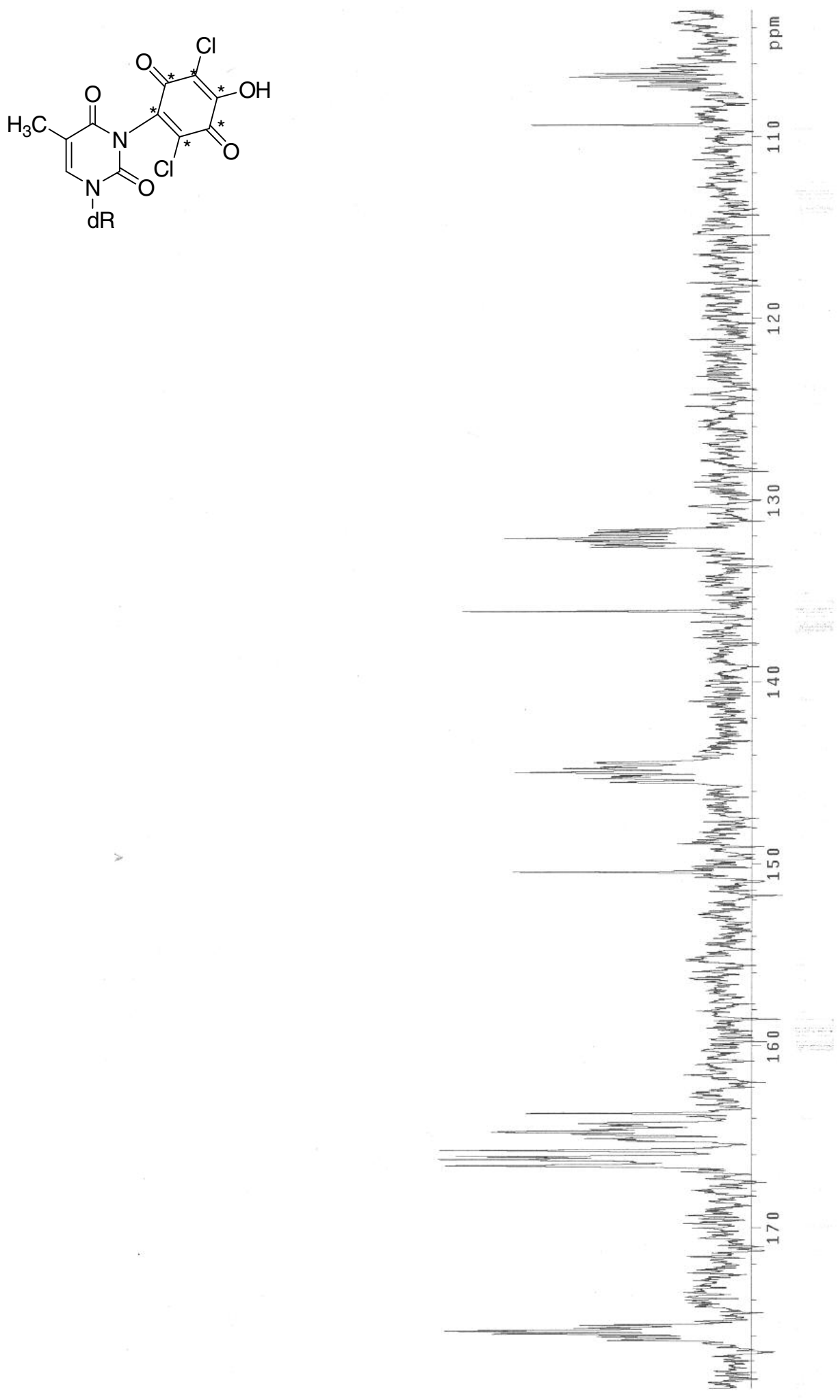
Figure S4

A

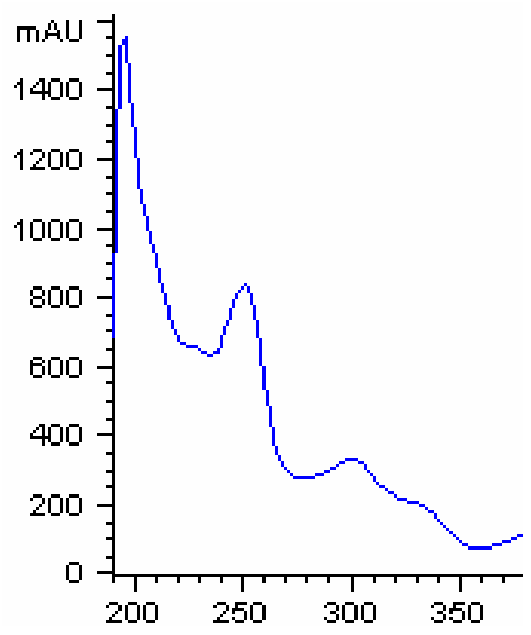

B

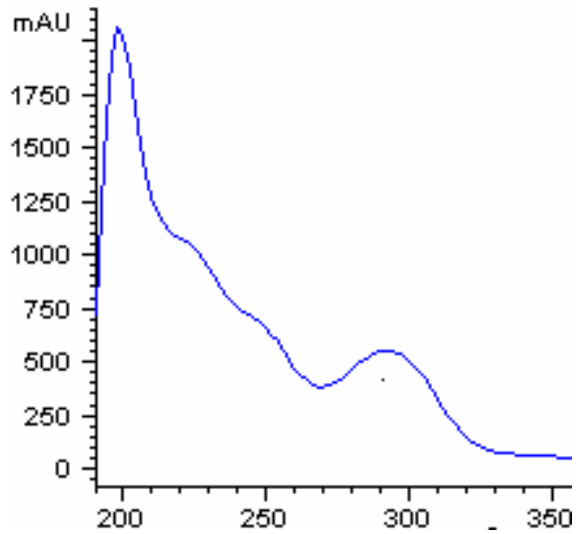




\section{Figure S5}

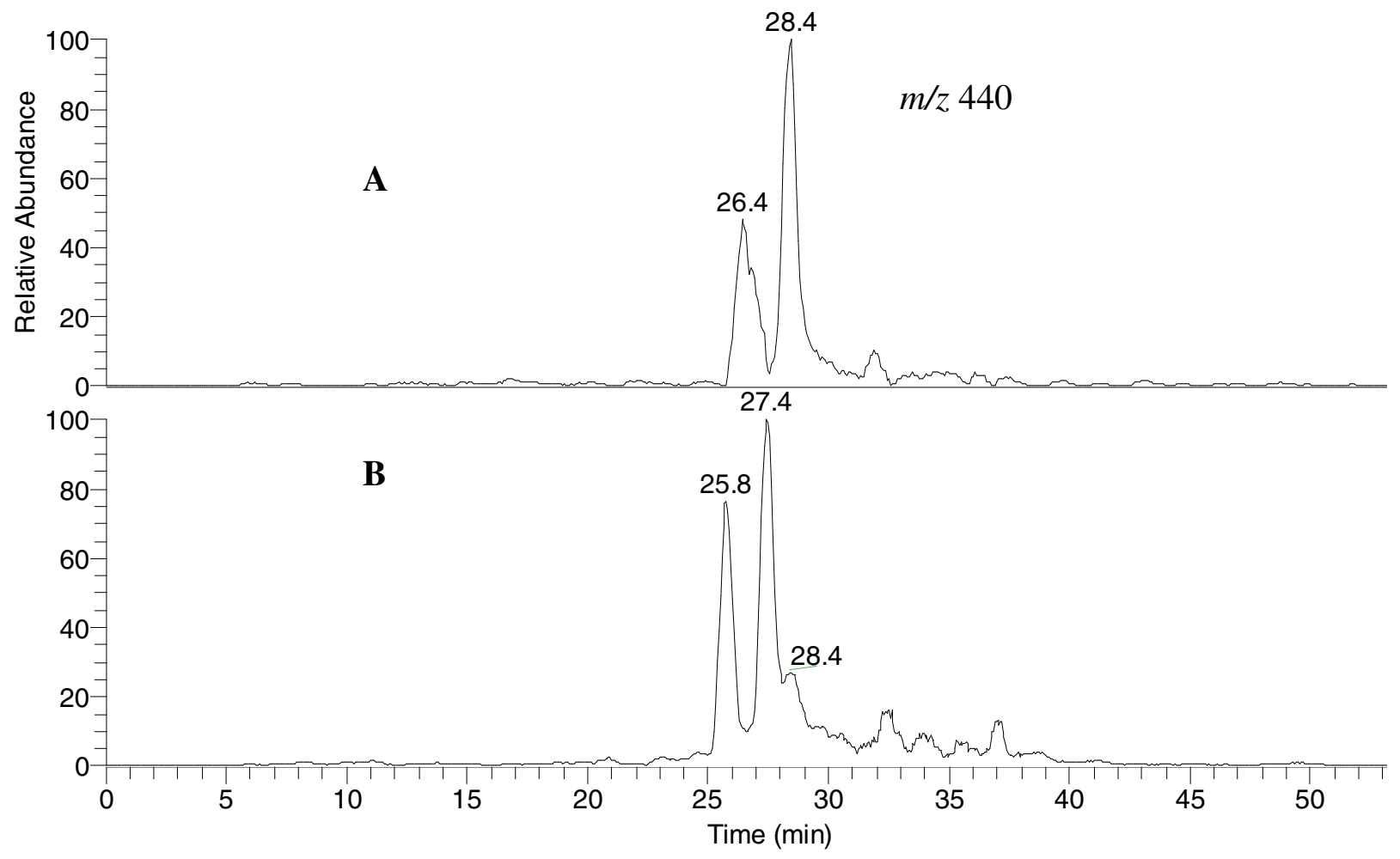


Figure S6

A.

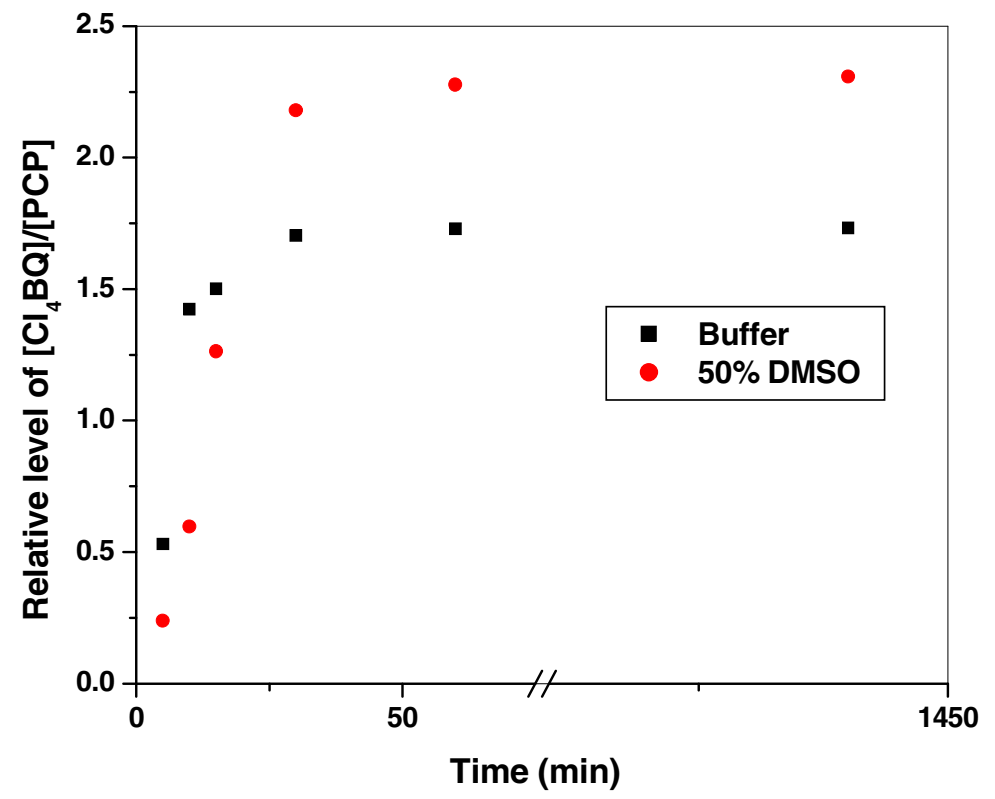

B.

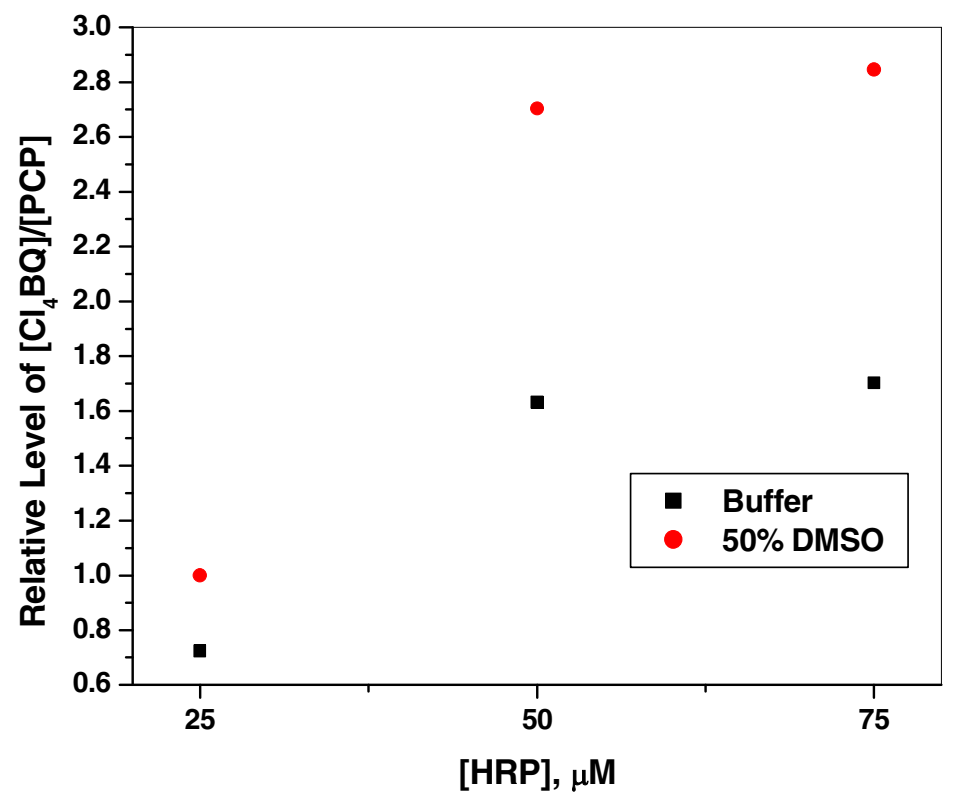

